Canadian Journal of Action Research

Volume 22, Issue 1, 2021, pages 27-44

\title{
LEADERS IN LIMBO: THE ROLE OF COLLABORATIVE INQUIRY INFLUENCING SCHOOL LEADERS' LEVELS OF EFFICACY
}

\author{
Pamela Adams \\ University of Lethbridge
}

Sarah Hamilton

University of Calgary

\author{
Dana Braunberger \\ Calgary Academy \\ Bonnie Caldwell \\ University of Calgary
}

\begin{abstract}
Using collaborative inquiry as a methodology for investigation, this study examined the implementation of a model of generative leadership (Adams et al., 2019) to explore the question: In what ways can implementation of a generative leadership model of professional learning for school leaders influence their sense of efficacy? An adapted model of generative leadership was adopted by seven school leaders in Alberta, Canada over a period of three years. Data was collected at the end of each year through journal reflections (Bashan \& Holsblat, 2017) to ascertain school leaders' levels of efficacy. Findings revealed four themes that identified how a generative leadership model influenced participants' effectiveness in their roles. These findings offer insight into how models of school leader professional learning might be re-imagined in order to positively influence their sense of efficacy.
\end{abstract}

KeY WoRDS: Efficacy; Leadership; Professional learning

\section{INTRODUCTION}

In their increasingly complex roles and responsibilities, school leaders (principals and vice principals) are expected to be facilitators of, rather than participants in, collaborative action research, assuming the role of instructional leader rather than lead learner. Often, the learning needs of school leaders are benignly neglected or - at best - prescribed, externally mandated, and episodic. Accordingly, learning leadership (Wood, 2020) has become characterized less by authentic sustained visible growth and more by haphazard experiences orchestrated or directed at the system level. Doing so often relegates the professional learning of school leaders to happenstance and reaffirms the image of the lone expert who, by virtue of positional authority, sits above the messiness of exploring, thinking, and learning. Yet, the school leader as visible lead 
learner (Timperley et al., 2020) is an important element in nurturing a school culture where learning for all is adopted as daily practice.

The role of collaborative inquiry in creating an alternate image of learning leadership has been under-investigated in the past decade. School leaders, such as principals and vice principals, are primarily viewed as facilitators of learning in others, usually teachers and other professional staff. An effective model to frame this professional learning is collaborative inquiry (Schnellert \& Butler, 2014). However, the experiences and voices of school leaders participating in collaborative inquiry to influence their professional learning and efficacy deserves further examination. How can a collaborative inquiry model be used by a group of school leaders to impact their sense of competence, their approaches to solving problems of practice, their reflection and reflective practice, and their overall sense of confidence in their leadership?

This article examines the activities of the Leaders of Learning Network (LoL), a group of seven school leaders that embarked upon a three-year collaborative inquiry into their professional learning. The study described here sought to explore answers to the question: In what ways can the implementation of a generative leadership model of professional learning for school leaders influence their sense of efficacy? First, literature is presented that intertwines three key concepts: instructional leadership as a competency of professional learning, efficacy as an outcome of professional learning, and inquiry-based growth as a method of professional learning. Next, a distinction is made between inquiry-based learning as an approach to professional learning and collaborative inquiry as a methodology adopted in this study. The process of implementing a Generative Leadership model undertaken by Network members is then outlined. Findings garnered through journal reflections are presented and discussed vis-a-vis conclusions to guide recommendations for central office leaders and external agencies seeking ways to enhance efficacy levels of school leaders, and for instructional and school leaders seeking ways to engage in opportunity for professional and personal growth.

\section{REVIEW OF RELEVANT LITERATURE}

This study was based on a foundation of the nexus between three concepts specific to school leader professional learning: instructional leadership, efficacy, and inquiry-based growth.

\section{Instructional Leadership}

From an American practice-based construct in the 1950s and 1960s, to the "effective schools" work of the 1980s, the 1979 publication of Edmonds' seminal article, Effective Schools for the Urban Poor identified strong instructional leadership as a feature of healthy and productive schools. What followed was a transition in emphasis from school principals as managers to school leaders as pedagogical experts, to school leaders as stewards of student learning (e.g., Bossert et al., 1982; Bridges, 1982; Erickson, 1979; Leithwood \& Montgomery, 1982; Murphy et al., 1985). The frameworks proposed by Bossert et al. (1982) and Hallinger and Murphy (1985) identified features of instructional management that were eventually encompassed in the broader construct of instructional leadership based on proficiency rather than formal authority (Blasé \& Blasé, 1999). In general, the earlier conception of instructional leadership consisted of mostly principalcentered instructional monitoring activities (Gumus et al., 2018). The current focus of educational leadership as an important influence on student learning rather than managerialism reflects the evolving scope of responsibilities of school leaders (Hallinger \& Kovačević, 2019). 
Instructional leadership has been defined in a variety of ways including "an influence relationship that motivates, enables, and supports teachers' efforts to learn about and change their instructional practice" (Spillane et al., 2003, p. 101), and "the effort to improve teaching and learning for PK-12 students by managing effectively, addressing the challenges of diversity, guiding teacher learning, and fostering organizational learning" (Brazer \& Bauer, 2013, p. 650). Key studies have noted that instructional leadership has a greater influence than other leadership approaches (Robinson et al., 2008; Shatzer et al., 2014).

Yet, challenges remain with the notion of instructional leadership, namely that activities that fall under the concept of leading learning comprise only one of several domains of action for school leaders (Murphy et al., 2016). Further, school leaders may not have sufficient expertise to effectively enact instructional leadership (Hallinger, 2003) and may not always be welcome visitors to the classroom, the site necessary for instructional leadership to occur (Hallinger et al., 2015). Despite these limitations, instructional leadership has an important, albeit indirect, influence on student learning and is becoming established as an important competency of contemporary educational leaders (Alberta Education, 2018; Kwan, 2020).

The notion of instructional leadership has been interpreted in various ways as one of several elements that constitute effective leadership. Around the world, particularly in countries in which a standards-based approach characterizes the definition of leadership, instructional leadership constitutes activities that range from the implementation of curriculum outcomes and assessment strategies, to the evaluation of staff or education of parents and community. In their synthesis of indicators of standards throughout Canada and internationally, Adams and Allan (2018) found only a handful of countries that explicitly identify instructional leadership as a required responsibility of school leaders, while dozens implicitly included the construct in a list of overarching competencies. In Alberta, the recently legislated Leadership Quality Standard (Alberta Education, 2018) is definitive in its use of the phrase, declaring that school leaders will "provid[e] Instructional Leadership" to ensure that "every student has access to quality teaching and optimum learning experiences" (p. 6). Accordingly, the construct of instructional leadership that informed this study was defined as "the leader's ongoing analysis of the context, and decisions about what leadership knowledge and abilities to apply, resulting in quality teaching and optimum learning for all school students" (Alberta Education, 2018, p. 3).

If instructional leadership is a required competency of effective school leaders, the extent to which they perceive they can achieve the multifaceted demands of this definition presents another layer of complexity in the enactment of instructional leadership by school leaders. Indeed, their perceived confidence in their competence to undertake high yield activities associated with instructional leadership may constitute a barrier to a positive and healthy sense of efficacy in school leaders.

\section{Leader Efficacy}

The role of an educational leader is complex by any definition and typically includes, at minimum, fostering relationships, managing resources, creating and nurturing a learning community, and leading instruction and learning. While the most common career trajectory for school leaders proceeds from teacher, to lead teacher, to assistant or vice principal, and eventually principal, little 
systemic support is provided at each step, resulting in an alarmingly low retention rate. Markin and Wang (2018) noted that "Research shows that most principals burn out and leave the profession in four years or less, although it takes five to seven years for a principal to have a significant impact on a school community" (para. 4).

For many new leaders, one source of stress contributing to attrition originates in their uncertainty about whether they are influencing student achievement and the feelings of isolation that accompany this uncertainty (McCormick, 2001). These remain emerging areas of study and, as Yukl (2012) posited, "The research on how skills can enhance the effects of leader behaviour is still very limited, and more studies are needed to discover how a leader's skills and personality traits influence the choice of behaviours and leader flexibility in adapting behaviors to different situation (p. 77). Yet, 35 years ago, Bandura (1986) proposed a theory that may offer a lens on leaders' levels of confidence in their ability to meet explicit organizationally mandated expectations.

Bandura's (1986) self-efficacy theory provides elements for consideration in an exploration of leaders' self-efficacy. His findings suggested that perceptions of efficacy are derived from four categories of experiences: enactive mastery, observational learning, social persuasion, and emotional states (Bandura, 1986). Self-efficacy can be enhanced, he posited, through opportunities to work through obstacles, observing success in others, assurance of others' belief in one's abilities, and being in a healthy emotional and physical state. Bandura's social cognitive theory contains, as a key strategy to enhance efficacy, the articulation of a goal or target. He noted that setting goals provides the motivation and commitment necessary to achieve the goal. Additionally, Bandura emphasized the role of modeling in efficacy development, a process he described as comprising adaptation rather than mimicry.

Often, self-efficacy occurs through a process of collaboration with others as leaders deconstruct and reconstruct their skills and knowledge as a function of participation in a community (Wenger, 1999). In the context of this study, a collaborative inquiry methodology was utilized to examine the impacts of an inquiry-based learning approach to improving self-efficacy, nested in a social constructivist epistemology (Vygotsky, 1978).

\section{Inquiry-Based Learning}

The notion of inquiry-based or problem-based learning has commonly been associated with instructional or pedagogical strategies used by grade-school teachers in the delivery of curricula. The approach has also been used in medical schools (Wood, 2003) with undergraduate technology students (Kurt, 2020), and as a professional development strategy with university professors (Adams, 2006). In a typical PBL setting, learning is triggered by a problem requiring resolution (Yew \& Goh, 2016) or, as described by Dewey (1910), a "perplexity, confusion, or doubt" triggered by "something specific which occasions and evokes it" (p. 12). Inquiry-based learning, combined with the premises of adult learning (Knowles, 1980), constitute one of the core elements of the generative leadership model.

\section{The Process: The Generative LeAdership Model}

In 2017, in an effort to form a supportive network of school leaders seeking opportunities to examine their instructional leadership practices and to enhance their sense of professional 
efficacy, the Leaders of Learning Network (the Network) was birthed. As a voluntary and informal group, the Network identified three primary foci for its work: (1) to engage in professional learning about leadership practice in ways that were different in scope and nature than had been previously experienced through conventional professional development events or training programs, (2) to collectively grapple with specific leadership issues that were emerging about which there were limited venues for sense-making, and (3) to build a dialectic skill set that could be used in a variety of contexts with educational partners. Originally numbering four (and eventually nine), participants agreed that a university partner would facilitate these reflective meetings. They also agreed that the bi-monthly sessions would be characterized by elements of collaborative learning based on social constructivist theory (Vygotsky, 1978) during which leaders would engage in authentic conversations about their leadership practice in the presence of other members of the Network. Reflective meetings were planned and facilitated with the intent of guiding leaders through cycles of de-construction and re-construction of their sense-making about instructional leadership practices. Accordingly, Network members met every other month for the purpose of reflecting on four questions:

1. What is the nature of your professional inquiry and what strategies have you implemented since we last met to further your work about this inquiry?

2. What have you learned about leadership in general and your leadership practices in particular as a result of your inquiry?

3. What data have you gathered that is evidence of this learning?

4. What will you undertake in the next 30 days to further pursue answers to your inquiry? (Adapted from Adams, 2020).

For purposes of this study, several aspects of Adams et al. (2019) framework of generative leadership were implemented with members of the Network:

1. Inquiry-based learning - Professional growth plans of school leaders were based on a problem in practice, grounded in a 'nagging' curiosity, and crafted in the form of a question during ".... a process in which educators commit to posing and answering essential questions about their professional practice over a sustained period (Adams, et al., 2019, p. 141). This aspect of the process was critical to situating the professional learning of school leaders in a process of learning rather than a mindset of reactive 'fixedness'.

2. Generative dialogue - As described by Adams, et al. (2019), "reflective questioning, when applied to conversations between professional partners, can help ensure that participants are more aware of false assumptions, contradictions, origins, implications, and consequences of their thinking" (p. 106). Over the three years of this study, this involved a dialectic conversation between colleagues in which the goal was to ask questions that cause reflection-on-practice. School leaders observed, practiced, and modelled generative dialogue with each other; in some cases, they also practiced the skill with teachers, students, and parents.

3. Sustained focus - Professional learning for and by school leaders can be event and crisis driven, based on emergent issues that originate outside of the leaders' locus of control. However, the professional learning of members of the Network was fluid in nature while still being persistent in focus. Essential questions were re-visited bi-monthly in an iterative way: some members of the Network revised their essential questions several times over 
the course of three years, while others changed their question on an annual basis, and still others maintained their focus on the same inquiry question for the entire duration of their involvement in the Network. As described by Adams et al (2019), “....professional learning is evidenced through multiple iterations (cycles, if you will) of pondering, deconstructing, reconstructing, and actualizing practice over a time frame that varies with each individual" (p. 130).

4. Generating and integrating evidence - The terms evidence-based or evidence-driven have become frequently used descriptors of how school leaders undertake informed problem solving. School leaders in the Network integrated research into their professional learning and inquiry; they were also simultaneously creating data gathering instruments and using evidence to make sense of their leadership practice; that is, they were both creators of evidence and consumers of research as they sought answers to their essential question of professional inquiry.

\section{ESSENTIALIZING THE QUESTION}

As described earlier, an overarching collaborative inquiry question guided the professional learning of the Leaders of Learning Network: In what ways can implementation of a generative leadership model of professional learning for school leaders influence their sense of efficacy? Additionally, each member of the Network was simultaneously pursuing answers to an individual inquiry unique to their leadership practice. Each essential question was linked to a provincially established standard of leadership quality (Alberta Education, 2018) and 'lived out' through strategies of implementation meant to inform an answer to the question. Additionally, data was gathered specific to the topic of each leaders' question to provide insight and consideration for future practice.

Crafting an individual inquiry question that captured the interest, spirit, and nuanced focus of each member of the Network constituted a challenging but necessary aspect of this process. These individual inquiries were specific in their focus in order to highlight the context of each leader's working reality; yet, they were also broad enough in scope to encompass representative aspects of instructional leadership as identified in the literature. In the context of the Leaders of Learning Network, each participant wrote and shared an essential question, rather than simply a goal, based on the prefix "In what ways will my...?". Three such examples of questions were:

- In what ways can I incorporate classroom observations into my leadership practice in a way that will enhance teachers' instructional practices?

- In what ways can my instructional leadership support a culture of growth through ethical practice and evidence-based decision making?

- In what ways will my explicit focus on the use of generative dialogue influence teachers' perceptions of support and effectiveness in the design of professional learning plans?

\section{METHODOLOGY}

The methodology undertaken in this study was based on the framework of collaborative inquiry described by several authors including Donohoo and Velasco (2016), Schnellert and Butler (2014) and Adam and Townsend (2014). This approach is closely related to a collaborative action research model referred to seminally by Levin (1946) and, later, Sagor (1992). Sagor (1992) identified this methodology as one in which educators could (1) improve student learning, (2) 
improve their own practice, (3) contribute to the development of their own profession, and (4) overcome the isolation commonly experienced by classroom teachers. The Centre for Collaborative Action research defines this process as one of deep inquiry into school leaders' professional interactions with others in service of moving towards an envisioned future (as referred to in Fine, 2018; McNiff, 2013; McNiff \& Whitehead, 2011).

\section{Collaborative Inquiry}

This study undertook a collaborative inquiry methodology to examine a process seeking to enhance leaders' collective agency and levels of professional individual efficacy. Yorks and Kasl (2002) identified collaborative inquiry as a methodology which offers "a systematic structure for learning from experience" (p. 3), taking place in professional learning communities where a researcher's own experiences are used to generate findings (Walther et al., 2017). Using this methodology, participants gather data through iterative cycles of inquiry, inclusive of their own reflections, actions, and perceptions, using these to generate knowledge to inform their practice and work towards an identified goal, all the while making meaning in context of the actions they undertook (Yorks \& Kasl, 2002). Grounded in the question: In what ways can implementation of a generative leadership model of professional learning for school leaders influence their sense of efficacy?, the collaborative inquiry methodology selected for this study followed a three-phased process described by Townsend and Adams (2009) as learning for practice, learning in practice, and learning from practice. Learning for practice involves the inquiry-based activities of readiness, awareness, and training engaged in collaboratively by the researcher and participants. Learning in practice includes planning and implementing intervention strategies and gathering and making sense of relevant evidence. Learning from practice includes culminating activities and planning future research.

\section{Participants}

The seven school leaders who voluntarily participated in this collaborative inquiry were employed in a metropolitan school division in Alberta, Canada. They varied in years of experience in leadership roles from one to seven in elementary and middle school settings. All participants earned Baccalaureate and Master degrees from a variety of post-secondary institutions across North America.

\section{Data Gathering Instruments}

Data was gathered over the course of three years through bi-monthly reflective journals of participants. Reflective prompts were provided by the facilitator and participants using a free-fall method (Adams, 2019) to explore their thinking on a variety of leadership topics. Reflections were hand-written for lengths of time varying from 15 to 30 minutes.

The use of reflective journals as a data source (Bashan \& Holsblat, 2017) has been critiqued as reflexive and potentially untrustworthy; however, in the case of this study on participants' perceptions of their leadership efficacy, journals offered rich themes that were analyzed to uncover how participation in collaborative inquiry with the Leaders of Learning Network was positively and negatively influencing aspects of confidence in instructional leadership competence. The anchor questions that guided our analysis of participants' reflections included: 
- What is your definition of the phrase 'leader efficacy'? What does it mean to you as a school leader?

- In what ways did the Network influence your level of self-efficacy to lead?

- How did your participation in the Network contribute to your professional learning as a leader?

- What aspects of the process had the greatest positive impact on your instructional leadership?

- What were challenges to your participation in the Network?

Answers to these questions were thematically analyzed using Neuman's (2011) process of analyzing qualitative data as one that seeks to "systematically organize, integrate, and examine" (p. 507). He contended that this process involves identifying general ideas, themes, and concepts that are found within the interview transcripts based on three types of coding: open coding involving a first preliminary pass through the data that was collected to identify main themes or ideas; axial coding involving creating organized codes, themes, and preliminary concepts in order to identify commonalities between categories and concepts; and selective coding involving finding exemplary cases and statements that help to more clearly illustrate the emergent themes.

\section{FINDINGS}

Journal reflections were analyzed post-hoc based on the anchor questions provided above using Neuman's (2011) process, which provided themes regarding (1) participants' definition of efficacy, (2) influence of the Network, (3) professional learning about leadership, and (4) the impact of the Network on leadership practices.

\section{Definition of Efficacy}

The first response question focused on participants' perceptions of the meaning of leader efficacy. Analysis identified three themes school leaders considered to be characteristic of the definition: confidence in competence, ability to support others, and self-understanding.

\section{Confidence in Competence}

The word confidence was used by all school leaders, often repeatedly, to describe their definition of efficacy. This confidence was broadly described vis-à-vis their professional competence; in the case of these participants, it was framed by their perceived ability to achieve aspects of the Leadership Quality Standard (Alberta Education, 2018). For example, Participants X and Y spoke of feeling "secure" that they were meeting or exceeding leadership competencies, specifically regarding taking informed and reasoned actions and making decisions that would "help move my teachers in...improving their pedagogical practice."

Participants also defined efficacy by their capacity to effectively anticipate and respond to emerging unexpected circumstances. One participant stated that "[This] is based on Bandura's concept of how well an individual can take action to successfully engage with situations". In this sense, participants were indicating that efficacy is a construct associated with both a feeling and with a set of demonstrable actions. 


\section{Supporting Others}

The notion of supporting others as an element of efficacy included references to working with teachers to "create a space for teachers to achieve their goals" and, more broadly, as "belief in my ability to support others in attaining their own personal goals and the goals of the community". It appeared that when leaders believed they were working with students, teachers and staff, and members of the school community, they felt efficacious, and these feelings characterized their definitions.

Supporting others also included creating a school environment that accommodates "conditions to support success". This expands the definition beyond supporting others in their goal attainment to feeling efficacious when structures and supports are implemented through which "[I] can demonstrate the confidence in others that they can achieve their goals". Participant Z indicated that "[I] came to an awareness that efficacy was not just what the great leader does themselves, but how they support those they lead. This was...a new perspective for me".

\section{Self-Understanding}

School leaders indicated that an understanding of their professional identity and being mindful of the influence of their decisions on others were important aspects of efficacy. One member described this as "a greater awareness of the characteristics of leadership". Another participant identified this process as "coming to feel more like myself". A feeling of "not feeling comfortable with my understanding" was noted as an antithesis to feeling efficacious as a school leader. Reflection was one strategy that leaders indicated to be essential in coming to this selfunderstanding.

\section{The Influence of the Leaders of Learning Network}

In response to question two, participants were asked to identify the primary areas of influence they experienced during their involvement in the Network by responding to the question: In what ways did the Leaders of Learning Network influence your level of self-efficacy to lead? Three themes emerged from their responses: commitment to reflection, heightened self-awareness, and confidence to share.

\section{Commitment to Reflection}

For participants in the Leaders of Learning (LoL) Network, a key area of influence resulting from their involvement was a commitment - or perhaps, re-commitment - to reflection. All participants noted that the Network provided time to reflect on action and ponder next steps. Participant X stated that: "the Network meetings provided pause in the space and silence afterwards to have time to think about and journal what occurred and what was learned". Participant W spoke of her participation as the "first real time I have sat down and discussed aspects such as leadership with a group of leaders".

Reflecting on the "why" of decisions was also seen to be an important aspect of influence. Participant X believed that "the LoL Network provided me with points of reflection to improve my own practice". Another participant described that her level of self-efficacy to lead was not an area she purposefully considered when building her leadership competencies. However, the reflective process offered "a reason to consider" this and other areas of her leadership practice. Some participants referred to this influence as a "pause" to listen actively to others' experiences, to re- 
examine their own circumstances, and to come to a place of confidence in enacting a plan of action. Reflection also was seen to contribute to a re-calibration of the nature of their work and their ability to prioritize numerous demands.

In addition, participants believed that their post-meeting reflections - the time after the Network sessions - were when deeper, contextually based thinking occurred.

\section{Heightened Self-Awareness}

Participants perceived that the Network encouraged iterative moments of examination of their leadership competence. They acknowledged the influence of opportunities to deconstruct and reconstruct their understanding of leadership practices through ongoing conversations about "the nexus where theory meets practice". In this way, the Network was seen to offer a process through which each leader could examine their own professional context through an understanding of positionality, leadership values, and ultimately decisions about taking action. The opportunity to be involved in a generative dialogue with leadership colleagues created conditions for leadership self-awareness, which then promoted alignment between system, school and personal priorities.

\section{Confidence to Share}

The notion of trust and vulnerability was identified by participants as another influence of the Network. Despite coming from various locations and personal backgrounds, participants all identified the value in hearing other leaders share their uncertainties that resulted from, and contributed to, an environment of trust. This influence was described variously as safe, relational, supportive, and camaraderie. For Participant Y, the process offered a "safe place to share insecurities and wonders and provided necessary feedback". Another believed that her involvement resulted in her grappling with problems of practice in ways that were "rigorous and empathetic".

\section{Professional Learning About Leadership}

When participants in the Network were asked to reflect on how the Network contributed to their professional learning, consistent themes emerged. Participants identified the unique nature of their learning, the processes and structures that guided this learning, and the critical role of reflection. The process of generative dialogue was specifically identified as being at the heart of this work. When describing the experience of learning, the metaphor of "space" also featured prominently.

\section{Unique Professional Learning Experience}

Participants shared that the Network was a unique professional learning experience, based in a desire for "improvement", "growth" and, the need "for something personal that would allow me to reflect on my own leadership competencies and move towards growth according to my needs". There was a general sense that while some professional learning experiences were provided by districts or graduate programs, the personal and practical exploration of the enactment of leadership was absent. Another unique feature of the learning within the Network was that individual personal leadership experiences were shared, not only as a strategy to solve problems, but to foster a way of thinking that "could be applied to any problem". In this way, confidence was seen to be built from increased competence in learning through meaningful problems of practice. 


\section{Processes}

Participants identified specific processes and structures that stimulated professional growth. The core feature was the use of generative dialogue. Generative conversations were seen as the source of creating actionable knowledge and confidence. Rather than advice-giving, frameworks and questioning paths provided the tools to support richer ways of thinking. This enabled leaders to coalesce their experiences, expertise, and perspectives to create meaningful plans of action. The embedded accountability in this process was also understood to be a key feature, as it was critical for participants to "challenge" each other to act within a 30-day action plan. These plans were based in evidence and designed to produce tangible results that were meaningful to the leader. The results sought were both personal, such as to "support the impact I can have as a leader" and contextual, identifying such issues as staff supervision, professional development design, and school improvement initiatives. This process was dynamic and, through ongoing reflection, the generative dialogue process provided repeated opportunities to practice the application of this approach.

\section{Space and Place}

Metaphors of space and place were used to describe the experience of learning during a Network meeting. When participants met, the setting provided an opportunity to expand thinking beyond their day-to-day thinking routines, to "think about the bigger picture" and to consider multiple perspectives and approaches. Space was referred to both as the physical gathering outside regular contexts that marked a break from their regular activities, but also included online meetings where meetings, independent of proximity, created a metaphorical space that permitted a reflective shift and promoted a shift in perspective. As leaders aspired to make meaningful changes in their understanding and practice, it was also imperative that a "safe space" was created where vulnerabilities and insecurities could be expressed.

Further, the collective investment in creating this "space" was fostered through active participation by participants. In this way, learning occurred through the use of generative dialogue to explore problems of practice, offering provocations to the thinking shared by others, and active listening as it provided "space to listen to the work of others, their struggles, insights and epiphanies". This engaged curiosity fostered greater understanding of self and how to align system, school and personal priorities and the value of the alignment within this space. As such, participants noted the reflections were "richer and deeper" than they would have been without participation in this "space".

Participants noted that this space and place for learning was personally transformational. Rather than focusing exclusively on actions and plans, participants aspired to "realize myself as a wise leader and understand who I am in this work". The Network provided participants the space to be both deeply resident in their current state and imagine possibilities. One participant noted that "leadership is understanding yourself" and this network "provides me the space to be myself".

\section{Impact on Instructional Leadership}

When asked to identify aspects of the Generative Leadership process that had greatest impact on their instructional leadership, participants reflected on both the processes within the network structure and opportunities to engage with the network and other leaders. Several consistent themes emerged in responses, including support from peers, a space and place for reflection, 
deeper understanding, and opportunities to consider additional perspectives. Additionally, much of the impact on instructional leadership was perceived to be a result of the generative dialogue approach implemented throughout the Network.

\section{Support of Peers}

Participants shared that the Network was a cohort of growth minded leaders who offered support and shared frustrations, concerns, and successes in a safe space. They identified feeling comfortable with sharing curiosities and how doing so provided them with informed optimism and collaboration that felt like collective efficacy. As Participant W shared, "[r]ather than feeling like I was on an island solving my problems alone, this process provided a sense of camaraderie, direction, and informed optimism that I could have a positive impact on whatever circumstance I was facing".

\section{Space and Place for Reflection}

The opportunity to reflect was seen to be invaluable for Network members. The commitment to a 30-day plan of action challenged participants to look to a short-term way to determine next steps for productive action. Participants agreed that this process was otherwise missing in their day-today practice. Respondent Y recognized that, "although my system offered some leadership support, I needed something personal that would allow me to reflect on my own leadership competencies and move towards growth according to my needs".

\section{Deeper Insight and Understanding}

Though less frequently discussed, most participants identified another result of their involvement in the Network was a deeper understanding and awareness of themselves as leaders. This learning included a "better understanding of how to align priorities", "shared understanding [and] commonalities" and a "deeper insight into problems". Responses highlighted a better understanding of important themes emerging in their work, along with increased confidence and knowledge to build effective competencies as leaders.

\section{Multiple Perspectives}

The structure and process of collaborative inquiry enabled participants to hear from others and consider problems from multiple perspectives. Aspects of seeking and gaining those multiple perspectives were identified as key moments in participants' responses, and respondents indicated they became more confident demonstrating collaborative decision-making informed by multiple perspectives.

\section{Discussion}

The importance of space and place for reflection, the uniqueness of the professional learning experience, and a culture of support and trust were themes throughout the findings. Further, greater self-awareness and understanding were seen as important outcomes of engagement in the work. Based upon a framework of generative leadership, four elements will provide a framework for the discussion: inquiry-based learning, generative dialogue, sustained focus, and gathering and integrating evidence. 


\section{Inquiry Based Learning}

Grounded in the practices of participants, a process of inquiry-based learning provided a means for Network members to engage in curiosities rooted in their own personal contexts and design action to develop a greater sense of their own self-efficacy. By formulating questions based on tangible problems, participants recognized the power of inquiry to engage in solution-seeking, help create actionable plans, and positively impact their learning communities. In this way, inquiry-based learning was meaningful, evidence-based, and individually impactful.

\section{Generative Dialogue}

The process of generative dialogue was identified by participants as an integral element of their professional growth. Engaging in generative dialogue promoted exploration of problems of practice, fostering rich learning, and promoting self-awareness to build the self-efficacy participants were seeking. Through sharing individual experiences and perspectives, new ways of thinking emerged and opportunities for further investigation were identified. Generative dialogue was seen at the "heart of the work" and enabled leaders to synthesize their learning, reflect on a range of possible ways of thinking, and create personalized action plans to better themselves and their practice.

\section{Sustained Duration}

Network members shared the belief that the time given for reflection over the course of their participation was essential for their growth. By continuing to return to their inquiry question when engaged in generative dialogue, they were able to reflect on their actions and to ponder their next steps. This sustained commitment to personal growth and the shared commitment to each other's success provided a safe space where leaders could be vulnerable and consider their leadership practice that was not otherwise available to them. Ongoing conversations provided time and space to grow awareness of their leadership and self-efficacy, while the iterative process provided occasion to create conditions for deeper learning to take place.

\section{Generating and Integrating Evidence}

The process of generative dialogue supported the creation of plans based in evidence. The emphasis on sharing this evidence supported personal accountability and offered a path to realize their goal of improving self-efficacy. Participants noted that this evidence helped them to better understand the complexities of understanding their impact and how they might align personal and system priorities. Reflection in, and of, practice was shared to be a key strategy towards greater self-understanding and self-efficacy.

\section{Challenges}

Participants identified several specific challenges to their perceived levels of efficacy and to the work of the Network. Their responses were consolidated into three larger themes: (1) time, expanding thinking, and (3) fidelity to the process. The limitations associated with time were described vis-à-vis demands to carve out a space and place between Network meetings to engage in authentic reflection on the extent and ways in which leadership goals were being achieved. Additionally, participants lamented that they did not have sufficient time to step away from the immediate demands of their leadership roles to reflect on the process from a "30,000-foot perspective". One participant acknowledged that she was "often too occupied with my perpetual 
to-do list". Another mentioned the time and effort necessary to maintain the regularity associated with the process; she felt 'guilt' when she was not able to engage at the level she wished.

The theme of expanded thinking was associated with challenges of making paradigmatic shifts, specifically regarding re-envisioning the nature and role of instructional leadership. One participant struggled when presented with options for "doing leadership differently. How can I do my IL [instructional leadership] work in different roles? As a lead teacher, vice principal, district leader?" Her challenges were linked to the challenge of maintaining fidelity to the process, regardless of role. Several participants mentioned that the skills of listening, questioning and taking meaningful action required conscious effort. One saw this as limiting her efficacy when "I didn't follow through on the work I had designed. When I revisited [my work] as part of our LoL group, the problems remained, and I hadn't taken much action...this was a lesson in how quickly things can get away from you when your focus is on day-to-day demands rather than on the process."

\section{ConClusion}

Leaders can develop their competency and confidence using several strategies, including structured reflection and learning from experience. In this study, it was clear that the Network provided a unique, personalized, and job-embedded form of professional learning that was not otherwise available to participants. Members of the Network noted that the norms established by the group created a safe space that allowed vulnerability while also offering meaningful analysis and feedback designed to promote solution-oriented reflection. Generative Dialogue provided the dialogic structure through which participants were able to make their thinking explicit, delve deeper into assumptions, and elicit richer insight into their problem of practice.

The processes and routines of generative dialogue established a way of thinking within the Network meetings as well as a mindset that participants drew upon when tackling problems within their daily leadership practice. These experiences promoted greater self-awareness and greater confidence in their own capacities to address leadership challenges. The Network provided a space for leaders to reflect, experiment, challenge, and learn about emerging problems in their leadership practice that was otherwise unavailable to them.

This study has implications for providers of leader professional learning, as well as for system leaders looking to re-imagine how they might increase the competence and confidence of school leaders. Indeed, further exploration might well seek to understand why these networks do not exist as part of a broader leadership development approach.

\section{REFERENCES}

Adams, P. (2020). Leadership development through action research: The journey of one school district toward collaboration, inquiry, and professional learning. In K. Clausen \& G. Black (Eds.), The future of action research: A Canadian perspective (211-231). McGill-Queen's.

Adams, P., \& Allan, S. (2018). Who uses a standards-based approach to improving professional practice, and why? In B. Stelmach \& P. Adams (Eds.), Optimum learning for all students, 
implementation of Alberta's 2018 professional practice standards: A literature synthesis. University of Calgary.

Adams, P,, Mombourquette, C., \& Townsend, D. (2019). Leadership in education: The power of generative dialogue. Canadian Scholars.

Adams, P., \& Townsend, D. (2014). From action research to collaborative inquiry: A framework for researchers and practitioners. Education Canada. https://www.edcan.ca/ articles/fromaction-research-to-collaborative-inquiry/

Adams, P. (2006). Transformative faculty development: improving university teaching through inquiry-based partnerships. Doctoral thesis. University of Calgary. http://doi.org/10 $.11575 /$ PRISM/369

Alberta Education. (2018). Leadership quality standard. Alberta Government. https://education.alberta.ca/professional-practice-standards/new-professionalstandards/

Bandura, A. (1986). Social foundations of thought and action: A social cognitive theory. PrenticeHall.

Bashan, B., \& Holsblat, R. (2017). Reflective journals as a research tool: The case of student teachers' development of teamwork. Cogent Education, 4(1), 1374234.

Blasé, J., \& Blasé, J. (1999). Principals' instructional leadership and teacher development: Teachers' perspectives. Educational Administration Quarterly, 35(3), 349-378.

Bossert, S. T., Dwyer, D. C., Rowan, B. \& Lee, G. V. (1982). The instructional management role of the principal. Educational Administration Quarterly, 18(3), 34-64.

Brazer, S. D., \& Bauer, S. C. (2013). Preparing instructional leaders: A model. Educational Administration Quarterly, 49(4), 645-684.

Bridges, E. (1982). Research on the school administrator: The state-of-the-art, 19671980. Educational Administration Quarterly, 18(3), 12-33

Dewey, J. (1910). How we think. Prometheus.

Donohoo, J., \& Velasco, M. (2016). The transformative power of collaborative inquiry: Realizing change in schools and classrooms. Corwin.

Edmonds, R. (1979). Effective schools for the urban poor. Educational Leadership, 37(1), 15-24.

Erickson, D. A. (1979). Research on educational administration: The state-of-the-art. Educational Researcher, 8(3), 9-14. 
Fine, M. (2018). Just research in contentious times: Widening the methodological imagination. Teachers College Press.

Gumus, S., Bellibas, M. S., Esen, M., \& Gumus, E. (2018). A systematic review of studies on leadership models in educational research from 1980 to 2014. Educational Management Administration \& Leadership, 46(1), 25-48.

Hallinger, P. (2003). Leading educational change: Reflections on the practice of instructional and transformational leadership. Cambridge Journal of Education, 33(3), 329-352.

Hallinger, P., \& Kovačević J. (2019). A bibliometric review of research on educational administration: Science mapping the literature, 1960 to 2018. Review of Educational Research, 89(3), 335-369.

Hallinger, P., Wang, W. C., Chen, C. W., \& Liare, D. (2015). Assessing instructional leadership with the principal instructional management rating scale. Springer.

Knowles, M. (1980). The modern practice of adult education: From pedagogy to andragogy. Cambridge.

Kurt, S. (2020). Problem-based learning. Educational Technology. https://educationaltechnology.net/problem-based-learning-pbl/

Kwan, P. (2020). Is transformational leadership theory passé? Revisiting the integrative effect of instructional leadership and transformational leadership on student outcomes. Educational Administration Quarterly, 56(2), 321-349.

Leithwood, K., \& Montgomery, D. J. (1982). The role of the elementary school principal in program improvement. Review of Educational Research, 52(3), 309-339.

Markin, G., \& Wang, F. (2018). Stress and burnout are on the rise among Canadian principals and vice-principals. Education Canada Network. https://www.edcan.ca/articles/burnoutprincipals-and-vice-principals/

McCormick, M.J. (2001). Self-efficacy and leadership effectiveness: Applying social cognitive theory to leadership. Journal of Leadership \& Organizational Studies, 8(1), 22-33. https://doi.org/10.1177/10719190100800102

McNiff, J. (2013). Action research: Principles and practice. Routledge.

McNiff, J., \& Whitehead, J. (2011). All you need to know about action research. Sage.

Murphy, J., Weil, M., Hallinger, P., \& Mitman, A. (1985). School effectiveness: A conceptual framework. Educational Forum, 49(3), 361-374. 
Murphy, J., Neumerski, C. M., Goldring, E., Grissom, J., \& Porter, A. (2016). Bottling fog? The quest for instructional management, Cambridge Journal of Education, 46(4), 455471, http://doi.org/10.1080/0305764X.2015.1064096

Neuman, W.L. (2011). Social research methods: Qualitative and quantitative approaches $\left(7^{\text {th }}\right.$ ed.). Pearson.

Robinson, V. M., Lloyd, C. A., \& Rowe, K. J. (2008). The impact of leadership on student outcomes: An analysis of the differential effects of leadership types. Educational Administration Quarterly, 44(5), 635-674.

Sagor, R. (1992). How to conduct collaborative action research. Association for Supervision and Curriculum Development.

Schnellert, L., \& Butler, D. (2014). Collaborative inquiry: Empowering teachers in their professional development. Education Canada.https://www.edcan.ca/articles/collabor ative-inquiry/

Shatzer, R. H., Caldarella, P., Hallam, P. R., \& Brown, B. L. (2014). Comparing the effects of instructional and transformational leadership on student achievement: Implications for practice. Educational Management Administration \& Leadership, 42(4), 445-459.

Spillane, J. P., Hallett, T., \& Diamond, J. B. (2003). Forms of capital and the construction of leadership: Instructional leadership in urban elementary schools. Sociology of Education, 76(1), 1-17.

Timperley, H. (2020). Leading professional learning: Practical strategies for impact in schools. ACER Press.

Townsend, D., \& Adams, P. (2009). The essential equation: A handbook for school improvement. Detselig.

Vygotsky, L. S. (1978). Mind in society: The development of higher mental processes. Harvard University.

Walther, J., Sochacka, N.W., Benson, L.C., Bumbaco, A.E., Kellam, N., Pawley, A.L., \& Phillips, C.M.L. (2017). Qualitative research quality: A collaborative inquiry across multiple methodological perspectives. Journal of Engineering Education, 106(3), 398-430.

Wenger, E. (1999). Communities of practice: Learning, meaning, and identity. Cambridge University.

Wood D. F. (2003). Problem based learning. BMJ (Clinical research ed.), 326(7384), 328-330. https://doi.org/10.1136/bmj.326.7384.328

Wood, K. (2020). Learning leadership: a dialogic phenomenon of high school principal practice (Doctoral dissertation, Lethbridge, AB: University of Lethbridge, Faculty of Education). 
Yew, H., \& Goh, K. (2016). Problem-based learning: An overview of its process and impact on learning. Health Professions Education, 2(2), 75-79.

Yorks, L., \& Kasl, E. (2002). Learning from the inquiries: Lessons for using collaborative inquiry as an adult learning strategy. New Directions for Adult \& Continuing Education, (94), 93-104.

Yukl, G. (2012). Effective leadership behavior: What we know and what questions need more attention. Academy of Management Perspectives, 26(4), 66-85.

\section{BIOGRAPHICAL NOTE:}

Pamela Adams is an Associate Professor of Educational Leadership in the Faculty of Education at the University of Lethbridge in Alberta. She has taught at the graduate and undergraduate levels since 1996, as well as served as the Faculty's Assistant Dean and liaison to the Alberta Initiative for School Improvement. Over the past five years, Pamela has conducted research studies in over 100 schools in seven districts throughout Western Canada, investigating themes of leadership, teaching effectiveness, adult learning, and essential conditions for professional learning using a collaborative inquiry model. Her work challenges educators to engage in a generative dialogue that shifts how colleagues talk with each other to create reflective action in teaching that leads to optimized student learning.

Dana Braunberger is a passionate educator, researcher, and university instructor, fiercely committed to building leadership that fosters future-focused learning cultures. Dana has been a teacher, principal, Chief Performance Officer, and currently leads Research and Innovation at Calgary Academy. With decades of experience in K-12 education and as a Doctor of Education candidate, her research interests include professional learning, innovation, practical applications of neuroscience, professional learning networks, and research practice partnerships. Her work is fueled by the potential of those who envision transformative opportunities and bring innovation to life.

Sarah Hamilton is presently a doctoral candidate at the University of Calgary. She completed her Master of Education in Mathematics Research and Learning at the University of Calgary. She currently works as an educational researcher and numeracy specialist at Calgary Academy, with a focus on supporting exceptional learners. Her teaching and research interests include mathematics education, learning disabilities, professional learning, research-practice partnerships, self-regulation, and collective knowledge.

Bonnie Caldwell is a school principal in Alberta and a doctoral candidate at the University of Calgary. She earned her Bachelor of Education degree at the University of Calgary and her Master of Education in Educational Leadership degree at the University of Lethbridge. Her areas of research include leadership, inclusive education, teacher induction, and post-secondary teacher education. 